\title{
UAV routing with genetic algorithm based matheuristic for border security missions
}

\author{
Muhammed Kaya and Omer Ozkan* \\ Department of Industrial Engineering, National Defence University, Turkish Air Force Academy \\ 34149, Yeşilyurt, Istanbul, Turkey \\ 3410kaya@harbiyeli.hho.edu.tr, o.ozkan@hho.edu.tr
}

\section{ARTICLE INFO}

Article history:

Received: 30 September 2020

Accepted: 26 March 2021

Available Online: 19 April 2021

Keywords:

UAV routing

Genetic algorithm

Matheuristic

Border security

Homeland security

AMS Classification 2010:

90C11, 90C59, $90 C 90$

\begin{abstract}
In recent years, Unmanned Aerial Vehicles (UAVs) are a good alternative for the problem of ensuring the security of the borders of the countries. UAVs are preferred because of their speed, ease of use, being able to observe many points at the same time, and being more cost-effective in total compared to other security tools. This study is dealt with the problem of the use of UAVs for the security of the Turkey-Syria borderline which becomes sensitive in recent years and the problem is modeled as a UAV routing problem. To solve the problem, a Genetic Algorithm Based Matheuristic (GABM) approach has been developed and 12 scenarios have been created covering the departure bases, daily patrol numbers, and ranges of UAVs. GABM finds the minimum number of UAVs to use in scenarios with the help of a GA run first and tries to find the optimal routes for these UAVs. If GABM can find an optimal route for the determined UAV number, it decreases the UAV number and tries to solve the problem again. GABM proposes a hybrid approach in which a metaheuristic with a mathematical model works together and the metaheuristic sets an upper limit for the number of UAVs in the model. In computational studies, when compared GA with GABM it is seen that GABM has obtained good results and decreased the utilized number of UAVs (up to $400 \%$ ) and their flight distances (up to $85.99 \%$ ) for the problem in very short CPU times (max. 122.17 s. for GA and max. 46.39 s. for GABM in addition to GA).
\end{abstract}

$(c)$ EY

\section{Introduction}

Ensuring the border security for the countries is one of the critical necessities to maintain homeland security. Creating smart borders by using intelligence and technology with national and international cooperation and coordination can increase to achievement possibility of the border security missions. Smart borders can prevent terrorist attacks, organized crimes, cyber-crimes, the passage of illegal drugs, and illegal migrants through borders [1].

Traditional border security can be maintained by fences, barriers, walls, towers, manned, animal and vehicle patrols, etc. When technology is added to the process in recent years; binoculars, cameras, radars, mobile surveillance equipment, radio, and cell phone data surveillance equipment, helicopters, zeppelins, planes, satellites, wireless sensors, Wireless Sensor Networks (WSNs), autonomous ground vehicles and robots, and Unmanned Aerial Vehicles (UAVs) are the

${ }^{*}$ Corresponding author main instruments that are proposed by the literature and implemented by the authorities.

Sensors and WSNs are studied to secure borders. "BorderSense", a hybrid WSN concept is introduced by [2]. "OptaSense", a distributed acoustic sensing system that uses acoustic and seismic sensing with fiber optic cables is developed for border security missions and presented by [3]. Decentralized smart sensor scheduling for multiple target tracking for border surveillance is studied by [4]. The deployment of the sensor is optimized by [5] for border surveillance. Large scale border security systems are modeled and simulated with "OPNET" by [6]. By [7], a brief survey about using WSNs for border security and intruder detection is presented and a bi-level exposure-oriented sensor location problem for border security missions is covered by [8].

A method for guidance and control of an autonomous vehicle in problems of border patrolling and obstacle avoidance is proposed by [9]. The "TALOS" project 
aiming to guard European Union borders with autonomous robotic vehicles is shared by [10,11]. UAVs are proposed for border security, for instance, hierarchical control architecture for a system involving multiple UAVs is proposed by [12]. A paper [13] is published to discuss the implementation of UAVs at borders and the navigation of UAVs on borders is studied by [14]. A report [15] is examined the strengths and limitations of using UAVs along the borders and related subjects for USA Congress.

The study [16] explores the different features when a four-rotor UAV is deployed to the USA's borders and territories. The paper [17] examined the threats and counter responsibilities that require the utilization of UAVs in homeland security. A report [18] is prepared to determine the effectiveness and cost of the UAV programs for border protection by the U.S. Department of Homeland Security. Border surveillance using multiple UAVs in coordination with alert stations including ground sensors along the borderline/fence is proposed by [19]. The usage of UAVs is also examined for search and rescue operations by [20]. Especially, the hybrid systems that combine some of these instruments above with intelligence and data analysis are studied in the last decade.

In the literature, mathematical models [5,8,21], simulation models $[6,12,19,22,23]$ and heuristics/ metaheuristics [1,5,24] are used to solve border security based problems. U.S.-Mexico border is the most studied border $[13,15,18,25,26]$. There are also studies about Turkey [22] and Spain [27]. The first and the only paper (as we may found) about the border security of Turkey is mainly using a simulation approach to model the border security system of Turkey and including border patrols, ambushes, sentries, thermal cameras, and askarad in the simulation model. However, in our paper, we tried to integrate the UAVs into the border security system as with real-life scenarios.

The usage of UAVs increased in recent years for missions in both military and civilian fields; such as intelligence, surveillance, reconnaissance, monitoring, destruction, communication, search and rescue, transportation, etc. The UAVs are chosen for that kind of mission because they are reliable, secure, longranged, remote-controlled (if needed), easy to use, and cheap. The technological details and the opportunities about the UAVs can be found in [28], a literature survey on quadrotor UAVs is presented in [29] and two review papers about UAVs are summarized in [30,31].

In this paper, the usage of the UAVs at the borderline between Turkey and Syria is studied. The internal conflicts in Syria have started in 2011 and since then the importance of the border between these countries is increased from the perspective of Turkey. Millions of civilian immigrants escaping from battles have come to the border. This situation forced Turkey to increase the security precautions on the border to prevent the passage of terrorists hidden in the civilian crowds through the border. A concrete wall through the border has been built. In addition to these precautions, this study is aiming to use UAVs for the security of the borderline between Turkey and Syria (i.e. over the concrete wall). Therefore, the problem can be thought of as an implementation of a UAV routing problem (UAVRP) or in general a vehicle routing problem (VRP).

VRP is a well-studied problem in the literature and there are optimal and approximate solution methods to solve the VRP. The first literature survey about VRP is presented by [32] published in 2009 and the second one is by [33] in 2016. The collaborative VRP is summarized in [34]. Capacitated [35,36], multivehicle, and multi-depot [37] versions are also studied in the past years. The traveling salesman problem (TSP) and its multiple salesman versions can also be examined to understand the simple nature of the problem [38,39]. Since the VRP and its versions have high-complexity, quite a lot of types of heuristics and metaheuristics are proposed to solve the VRPs in the literature.

After the increase of the usage of the UAVs for several missions, UAVRP in both $2 \mathrm{D}$ and $3 \mathrm{D}$ domains has also been studied in the literature. Similar to VRPs, UAVRP and its versions have complex nature; therefore mainly geometric methods, dynamic programming, mathematical models, heuristics, metaheuristics, artificial neural networks, learning-based methods, fuzzy logic, simulation models, etc. are studied in the literature [40,41]. Computational-intelligence based algorithms [42], evolutionary algorithms including differential evolution and genetic algorithm (GA) $[43,44]$, particle swarm optimization, ant colony optimization, simulated annealing [45], tabu search are mainly the proposed metaheuristics to solve the UAVRP and its versions [41]. 3-D UAVRP is reviewed by [46] and Flying Ad-Hoc Networks are also examined by [47]. The first difference between VRP and UAVRP is the distance calculation methods (i.e. Euclidean distance is preferred in UAVRP since the flight between two points can be done directly) and the second one is the usage of distance range constraint is a binding constraint for UAVRPs (if the UAV has not a capability to refuel in the air). Before the fuel of a UAV is finished, the UAV should be landed; therefore the distance range constraint should be a hard constraint. This hard constraint makes the model harder to be solved. In VRP on the land, the distance range constraint can be increased by refueling, therefore; it can be a soft constraint. These differences are considered in the model that this paper proposed.

In summary for the introduction and literature review section, there are different systems to secure borders in the literature. In addition to the traditional security systems, in recent years the usage of unmanned and robotic systems on borders is increased. UAVs are very good alternatives to be included in the border security systems in a hybrid manner but there are not many studies in the literature about this topic and we summarized the very few existing papers above. 
Therefore, as a contribution to the literature as far as we know this paper is the first paper that proposes a matheuristic approach (i.e. Genetic Algorithm Based Matheuristic (GABM)) to solve a UAVRP defined for real border security missions. The mathematical model is inspired by literature and adapted to the border security missions. A real UAV is preferred in the case study section and its specifications are used in real case scenarios. In this manner, this work tries to find optimal routes over the borderline of Turkey and Syria for real UAVs considering checkpoints, number of UAVs, number of daily patrols, flight ranges, and main bases that the UAVs take off and land. Generated 12 scenarios are considering real military airports near the border as main bases. The proposed GABM is trying to minimize the used number of UAVs and the traveling distances of the UAVs simultaneously.

This paper has been divided into sections as follows. The next section gives the problem definition and the mathematical model for the problem. The third section covers the details about the proposed GABM and the used GA in the GABM. The fourth section includes the case study part and provides the results of the computations on the case scenarios. The final section concludes the paper.

\section{The problem definition and the mathematical model}

The UAVRP can be described as a graph $G=(N, A)$ with a set of nodes $(N=1 . . n)$ and a set of $\operatorname{arcs}(A=1 . . a)$ with a set of UAVs $(M=1 . . m)$. The UAVRP can be formulated as a Mixed Integer Linear Programming (MILP) model, it is inspired and revised from [38,39] and presented below.

$$
\min . z=c_{d} \sum_{i=1}^{n} \sum_{j=1}^{n} d_{i j} \sum_{k=1}^{m} x_{i j k}+m c_{m}
$$

subject to:

$$
\begin{aligned}
& \sum_{j=2}^{n} \quad x_{1 j k}=1 ; \quad \forall k ; 1 \leq k \leq m \\
& \sum_{i=2}^{n} \quad x_{i 1 k}=1 ; \quad \forall k ; 1 \leq k \leq m \\
& \sum_{j=1}^{n} \sum_{k=1}^{m} \quad x_{i j k}=1 ; \quad \forall i ; 2 \leq i \leq n \\
& \sum_{i=1}^{n} \sum_{k=1}^{m} \quad x_{i j k}=1 ; \quad \forall j ; 2 \leq j \leq n \\
& \sum_{i=1}^{n} x_{i r k}=\sum_{j=1}^{n} x_{r j k} ; \quad \forall r ; 2 \leq r \leq n ; \\
& \forall k ; 1 \leq k \leq m \\
& \sum_{i=1}^{n} \sum_{j=1}^{n} d_{i j} x_{i j k} \leq R_{k} ; \quad \forall k ; 1 \leq k \leq m(7) \\
& v_{i}-v_{j}+(n-m) \sum_{k=1}^{m} x_{i j k} \leq n-m-1 ; \\
& \forall i ; \forall j ; 2 \leq i \neq j \leq n
\end{aligned}
$$

$$
\begin{aligned}
& x_{i j k} \in\{0,1\} ; \quad \forall i, j \in V ; \forall k \in U \\
& v_{i} \geq 0 \text { and } \in Z ; \quad \forall i \in N
\end{aligned}
$$

In the model, there are " $m$ " numbers of UAVs and " $n$ " number of nodes including 1 base station (i.e. first numbered node is the base station) and $n-1$ numbers of grid (i.e. check) points on the border. The arcs are the flight connection paths between nodes. The $d_{i j}$ is the Euclidean flight distance between nodes $i$ and $j$. The decision variables $x_{i j k}$ are used to represent the used route between nodes, that $x_{i j k}=1$ if the arc between $i$ and $j$ is used, otherwise $x_{i j k}=0$. The $R_{k}$ is the distance range limit of UAVs to finish the tour. In the model, $v_{i}$ and $v_{j}$ are the positions of node $i$ and $j$ in the path that is used to prevent the sub-tours.

The objective function (1) minimizes the total cost. The flight cost and the used UAV cost are creating the total cost. The $c_{d}$ is the 1-kilometer flight cost for a single UAV and $c_{m}$ is the unit UAV cost. Constraint (2) ensures that " $m$ " number of UAVs take off from node \#1 (i.e. base station) and Constraint (3) guarantees the UAVs turn back to the departure base. Constraint (4) and Constraint (5) ensure that it is necessary to visit all checkpoints. Constraint (6) guarantees that if a UAV visits a node, it also departures from that node and Constraint (7) limits the total tour distance according to the flight range of the UAVs. Constraint (8) is essential to prevent the sub-tours. Constraint (9) is defining the decision variables.

One of the main assumptions in this model is that the $\mathrm{UAV}(\mathrm{s})$ takes off from any base station and land at any base station. When UAV visits a node that means it can visualize and observe the borderline on that point. The UAV directly flies from one point to another without changing the route in any event that occurs, for instance, the detection of an intruder from the borderline. The UAV just informs the authorities when an event happens. The meteorological effects on the flight times are ignored and the regular speed of UAVs is assumed as constant. The breakdowns of UAVs on the air are also ignored and assumed that the UAVs are always operating. It is also assumed that the grid points have the same importance weight, since in the border security missions even one border violation may cause terrorist attacks in the homeland. Therefore, the security overall of the border should be maintained. However, if there are more difficult areas to be secured via UAVs, the precautions can be increased by using other traditional security tools (patrols, fences, concrete walls, sensors, cameras, etc.).

In the implementation of scenarios, the proposed model has been revised and able to solve multi-base station UAVRPs via changes in Constraints (2) and (3). In the revised model, there are " $o$ " numbers of base stations, and the " $m$ " numbers of UAVs can take off from any of these base stations and can land at any of them. 


\section{The proposed genetic algorithm based matheuristic}

The GA is a well-known and well-studied metaheuristic in the literature. According to the literature [41,43], the GA is the most-preferred metaheuristic to solve UAV routing-based problems and the effectiveness of this algorithm is presented in these studies. Therefore the GA is chosen for this study. The GABM is starting with running a problem-specific GA 30 times and the pseudo-code of the designed GA is presented below in Figure 1.

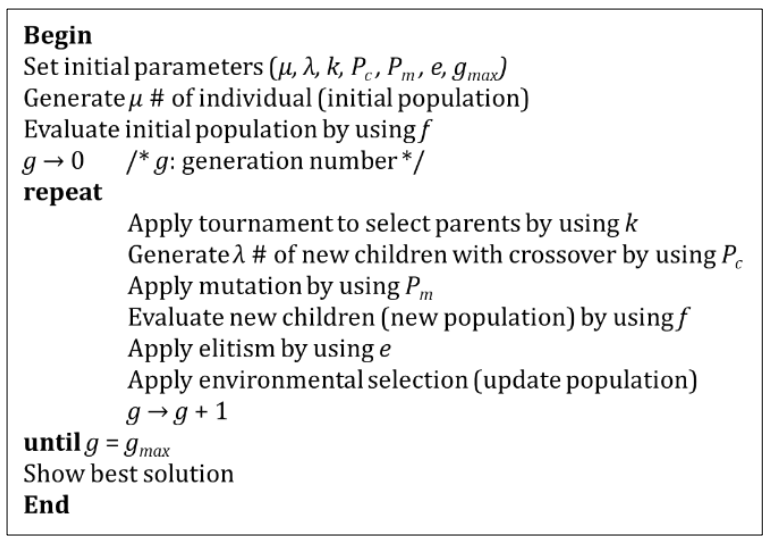

Figure 1. Pseudo-code of developed GA.

The designed GA starts searching with a group of solutions (i.e. a population) and generates better individuals (i.e. solutions) by implementing crossover, mutation, and selection operators through generations. The details about the GA are described in the following subtitles.

The proposed GA and the proposed mathematical model are hybridized in the GABM. The hybridization of optimization methods aims to use powerful sides of them in a single algorithm. The GA is used in GABM to determine the " $m$ " value of the proposed mathematical model. Since in the proposed model, if the " $m$ " value becomes a decision variable, the model becomes more complex. The GA helps the model to use the " $m$ " value as a constant parameter. Therefore, the GABM is trying to find an optimal solution to the UAVRP as described in Figure 2.

The proposed GABM acts to decrease the complexity of the UAVRP, and helps to find a faster solution. The used GA and its specifications are described in the following subtitles.

\subsection{Representation and fitness function}

In the GA, a problem-specific permutation-based representation is used to indicate the solutions. A simple example of the representation is presented in Figure 3.

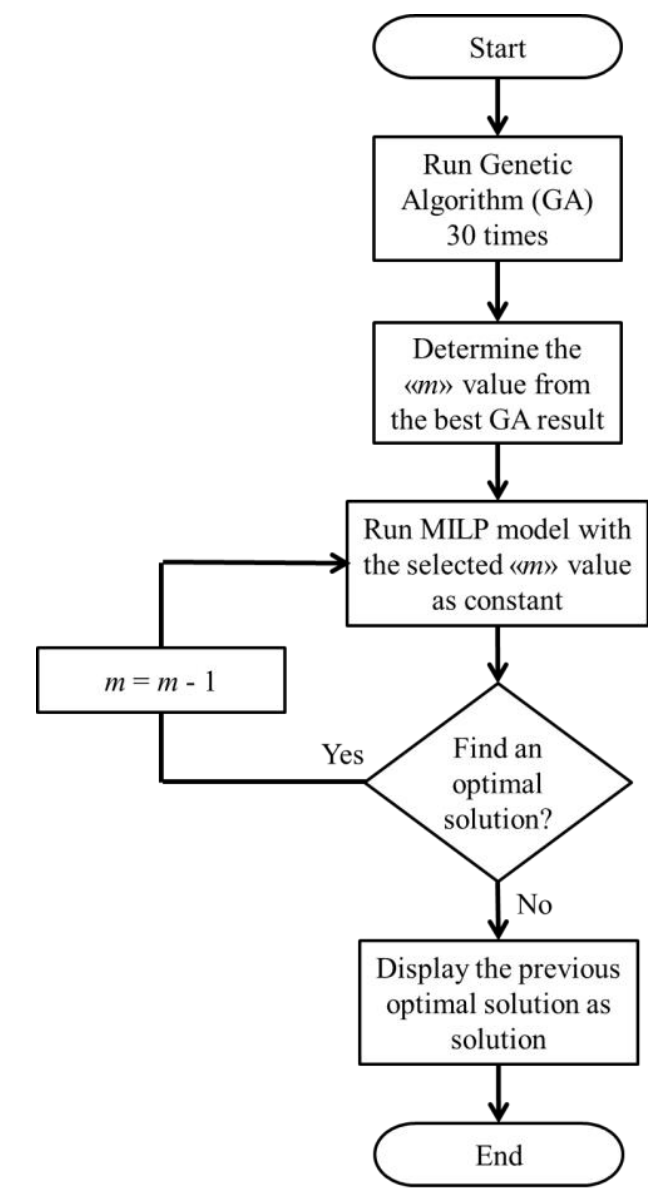

Figure 2. The flowchart of the proposed GABM.

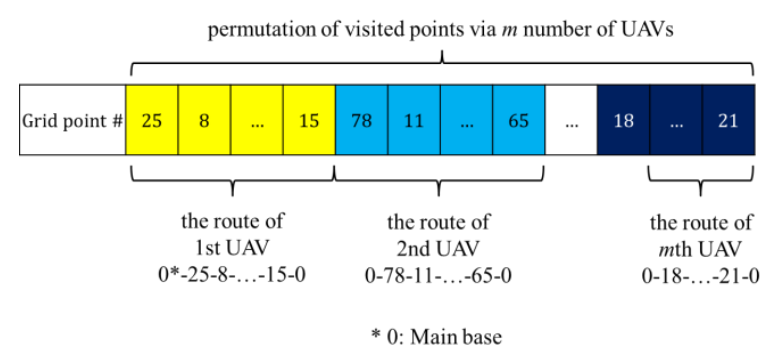

Figure 3. Permutation-based representation.

The permutation of the visited grid (i.e. check) points is showing the routes of the " $m$ " number of UAVs. As seen in the example, the first UAV is taking off from a base station, visiting the grid points $\# 25, \# 8, \ldots, \# 15$ (i.e. the yellow points) in order and turning back to a base station. The first UAV cannot exceed its flight range; therefore it cannot visit grid point \#78 and turns back to a base station. The second UAV continues to fly in a route from the grid points \#78,\#11,..,\#65 (i.e. the blue points) in order similarly. The UAVs always take off from or land to the nearest active base station. The order of the grid points indicates the routes of the all " $m$ " number of UAVs. The total cost (i.e. objective function) described in Eq.(1) is used as a fitness function for the solutions. The individuals with lower costs mean that they are better solutions. 


\subsection{Initial population and parental selection}

While generating $\mu$ number of solutions as initial population, five different strategies are used in GA. In the first strategy, when a UAV is monitoring the border on the field it is logical to fly from one grid point to its one of two neighbor points, therefore one individual of the initial population is simply starting from the first grid point and the route follows forward through the nearest neighbor points. The second solution is beginning from the last grid point and the route continues backward through the nearest neighbor points. The third strategy is to generate random individuals. For fourth and fifth strategies, random initial grid points are selected and the route continues forward or backward till the end or beginning points, respectively as type- 1 and 2 heuristics. The sample initial solutions are presented in Figure 4 when $\mu=20$.

\begin{tabular}{|c|c|c|c|c|c|c|c|c|c|c|c|c|}
\hline \multicolumn{13}{|c|}{ Initial population (total 20 individuals) } \\
\hline $\begin{array}{c}\text { Grid point } \\
\#\end{array}$ & 1 & 2 & 3 & $\cdots$ & $\cdots$ & $\cdots$ & $\cdots$ & $\cdots$ & ... & 150 & 151 & 152 \\
\hline \multicolumn{13}{|c|}{1 individual starting with first point to the end } \\
\hline $\begin{array}{c}\text { Grid point } \\
\#\end{array}$ & 24 & 25 & $\ldots$ & $\ldots$ & 152 & 1 & 2 & $\cdots$ & $\cdots$ & ... & 22 & 23 \\
\hline \multicolumn{13}{|c|}{1 individual starting with nearest point } \\
\hline $\begin{array}{c}\text { Grid point } \\
\quad \#\end{array}$ & 4 & 54 & 3 & $\cdots$ & $\cdots$ & $\cdots$ & $\cdots$ & $\cdots$ & $\cdots$ & $\cdots$ & 25 & 16 \\
\hline \multicolumn{13}{|c|}{2 individuals randomly } \\
\hline $\begin{array}{c}\text { Grid point } \\
\#\end{array}$ & 15 & 16 & $\ldots$ & ... & 152 & 1 & 2 & $\cdots$ & $\ldots$ & $\cdots$ & 13 & 14 \\
\hline \multicolumn{13}{|c|}{8 individuals with type- 1 heuristic } \\
\hline $\begin{array}{c}\text { Grid point } \\
\#\end{array}$ & 15 & 14 & ... & $\cdots$ & 1 & 152 & 151 & $\cdots$ & $\cdots$ & $\cdots$ & 17 & 16 \\
\hline
\end{tabular}

Figure 4. Sample initial population.

The tournament selection operator is used to determine parents in the proposed GA. In the tournament selection, the operator selects $k$ number of individuals randomly from the current population, and the solution with the lowest fitness wins the tournament and becomes a parent. The $\mu$ and $k$ parameters are tuned before the case study.

\subsection{Crossover and mutation}

The crossover probability $\left(P_{c}\right)$ is used to determine whether the selected parent can be a candidate in the crossover. The order- 1 crossover operator is selected to generate new children as seen in Figure 5.

The operator uses two parents and it selects two random breakpoints in the representation of the parents (i.e. yellow parts). The operator copies the grid points in the interval of selected breakpoints from the first parent to the child. The copying process continues with the second parent from the outside of the last breakpoint. The operator prevents generating infeasible children according to the permutation-based solution type and copies only the uncovered grid points in the current child from the second parent. When the last grid point of the second parent is reached, the operator turns back to the beginning point of the second parent. The process finishes when all grid points are covered in the child.

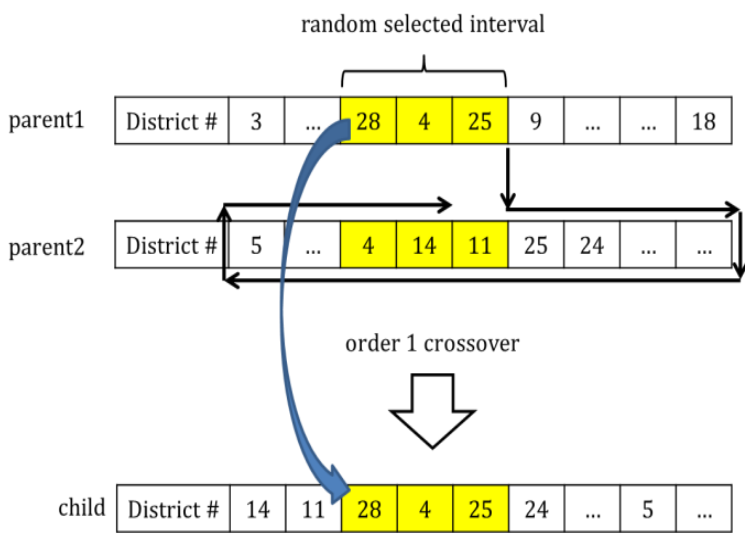

Figure 5. Order-1 crossover.

The swap mutation is used as the mutation operator as seen in Figure 6 and mutation probability $\left(P_{m}\right)$ is used to determine whether the generated new child can be mutated. The operator selects two random points from the child and swaps their positions. The $P_{c}$ and $P_{m}$ are tuned before the case study.

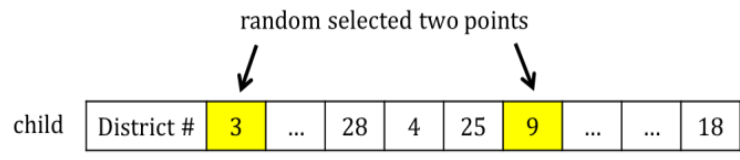

swap mutation

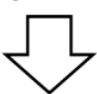

\begin{tabular}{c|c|c|c|c|c|c|c|c|c|c|}
$\begin{array}{c}\text { mutated } \\
\text { child }\end{array}$ & District \# & 9 & $\ldots$ & 28 & 4 & 25 & 3 & $\ldots$ & $\ldots$ & 18 \\
\cline { 2 - 9 }
\end{tabular}

Figure 6. Swap mutation.

\subsection{Environmental selection and stopping condition}

The GA generates $\mu-e=\lambda$ number of new children and with an elitist strategy; the best $e$ number of individuals of the previous population is added to the new generation. The $\mu$ stays constant through generations in the environmental selection. The GA stops when it reaches to $g_{\max }$ number of generations. The parameters are tuned before the case study.

\section{The case study and the results}

The border between Turkey and Syria is selected because the conflicts started in 2011 and not ended till 2021 in Syria. Millions of refugees migrated from Syria through Turkey. It is critical to observe the border to prevent the passage of terrorists hidden in the civilian crowds through the border. The borderline between 
Turkey and Syria is $910 \mathrm{~km}$ as seen in Figure 7.

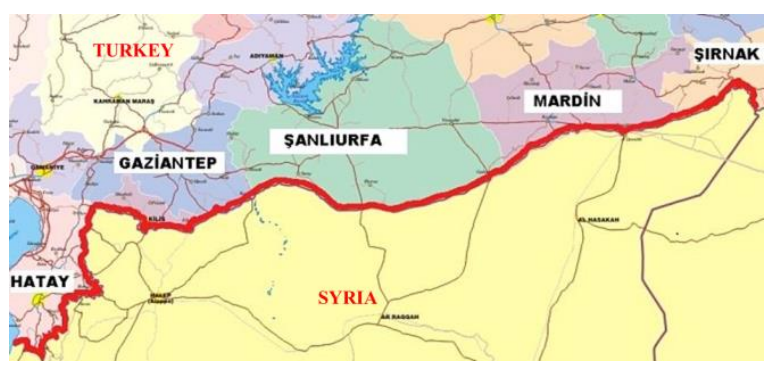

Figure 7. The borderline between Turkey and Syria $(910 \mathrm{~km})$.

The borderline is not a straight line and there are indentations and protrusions. Therefore 152 grid (i.e. check) points and 4 base stations nearest through the borderline (Adana, Diyarbakır, Batman, and Muş) are selected conveniently to the selected UAV. The Euclidean distance between the grid points is five kilometers and the grid points are covering the overall Turkey-Syria borderline. The base stations are representing the military airports in those cities. The selected bases and grid points are presented in Figure 8 .

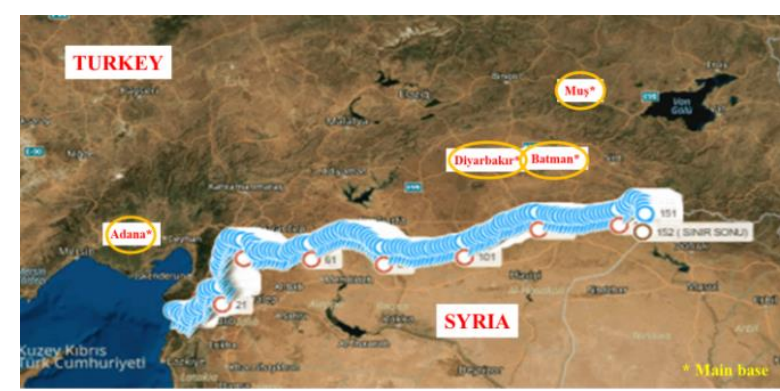

Figure 8. The selected 152 grid points and 4 main bases (Adana, Diyarbakır, Batman, and Muş).

The Bayraktar UAV [48,49] is selected for the case study because it is already using in these missions in real life. The Bayraktar is a long-ranged (3000 kilometers) Turkish made tactical UAV that is convenient for that kind of missions. We assumed that the unit cost of one UAV is $\$ 4,000,000$ and the unit cost of the 1-kilometer flight is $\$ 20$ to be used in the model. The Bayraktar can get the desired images and videos from that visited grid points by flying at a proper altitude. A sample figure for the coverage of the zones by visiting the grid points (i.e. red signs are representing the grid points in the borderline) in the center of the grid zones via a Bayraktar UAV is presented in Figure 9.

The 152 grid points (can be seen in Figure 8) are located based on the observing capabilities of UAV as in Figure 9 and covering all borderline from beginning to end. The scenarios in the case study section are generated according to the real-life necessities. 12 scenarios are considered covering active base station(s) and the number of daily patrols can be made by UAVs. The number of daily patrols is affecting the flight range of
UAVs as seen in Table 1.

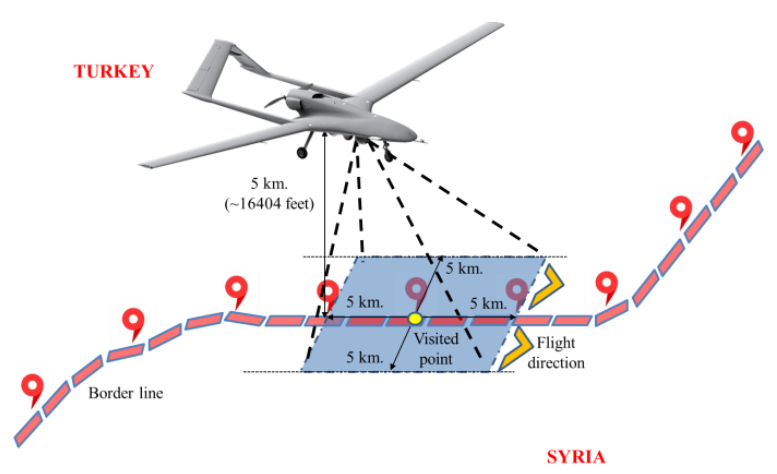

Figure 9. The usage of Bayraktar UAV for a border security mission.

Table 1. The scenarios.

\begin{tabular}{cccc}
\hline $\begin{array}{c}\text { Sce. } \\
\#\end{array}$ & $\begin{array}{c}\text { Active main } \\
\text { base(s) }\end{array}$ & $\begin{array}{c}\text { \# of } \\
\text { daily patrols }\end{array}$ & $\begin{array}{c}\text { Flight range } \\
(\mathrm{km} .)\end{array}$ \\
\hline 1 & Adana & 1 & 3000 \\
2 & Batman & 1 & 3000 \\
3 & Diyarbakır & 1 & 3000 \\
4 & Muş & 1 & 3000 \\
5 & Adana & 2 & 1500 \\
6 & Batman & 2 & 1500 \\
7 & Diyarbakır & 2 & 1500 \\
8 & Muş & 2 & 1500 \\
9 & All bases & 3 & 1000 \\
10 & All bases & 4 & 750 \\
11 & All bases & 5 & 600 \\
12 & All bases & 6 & 500 \\
\hline
\end{tabular}

In eight of twelve scenarios, it is considered that just one base station is active which means the UAVs can only be settled in those base stations. For the remaining four scenarios, all bases are thought of as active. Therefore, the UAVs can take off from one base station and can land at another base.

The parameters of the GA are tuned with experiments. 30 runs are done for each combination of the parameters by running with the candidate values in a selected scenario. The best-resulted values in 30 runs are used to determine the values for the parameters as seen in Table 2. The $\mu$ and $g_{\max }$ parameters are considered as pairs to make a fair comparison. $P_{c}$ is assumed as 1 .

The GA is coded in MATLAB, the MILP model is developed in ILOG and solved in CPLEX. The runs of GA and the MILP model are made on the same computer that has Intel Core I7-7700HQ CPU, 2.80 $\mathrm{GHz}$, and $16 \mathrm{~GB}$ RAM specifications. The scenarios are solved 30 times with GA and GABM used the best solution of GA to determine the " $m$ " value.

The summary results are presented in Table 3 . According to the results with the one active based initial eight scenarios, for six solutions the GABM found the same optimal solutions with the GA. But for two 
scenarios (i.e. scenario \#5 and \#8), the GABM improved the GA solutions and found the optimal solutions. Especially for scenario \#8, the GABM solution is using much less UAV than GA, since Muş is the furthest base station to the borderline. However, for the last four more complex scenarios, the GABM outperformed and improved the GA results much more. The used UAVs and the flown distances in GA results are extremely decreased in GABM results. The flight distances are reduced by more than near 1000 kilometers in some scenarios and at least one UAV is saved. According to the used active bases that are listed in the last four results; mostly Adana, Diyarbakir, and Batman bases are preferred to take off and land by the UAVs. Since Mus is the furthest base station to the borderline, it is not used in optimal routes.

Since the range distance is the most effective constraint in the results, the details about the flight distances, remaining flight ranges, and flight routes of each UAV for the results of the GABM are provided in Table 4 with the details about the scenarios (i.e. the \# of variables and the \# of constraints) are also covered. In scenarios, the \# of variables is changing for 1 to 4 UAVs as 23562, 46971, 48825, and 97497, respectively. The \# of constraints is also ranging 23411 to 23876 for 1 to 4 UAVs. According to the detailed results of GABM, when the \# of daily patrols increases and the flight range of UAVs decreases, the utilization based on flight distances of UAVs also increases as seen that the remaining flight ranges are smaller in the last scenarios (i.e. especially scenarios \#10, \#11, and $\# 12$ ). For scenarios with long flight ranges the Bayraktar UAV can accomplish missions with smaller utilization ratios based on flight distances.

The CPU times of the algorithms are presented in Table 5. The CPU times seem very reasonable for a UAVRP. The CPU times for GA are ranging between 71.89 to 122.17 seconds. The CPU times of GABM is varying from 2.92 to 46.39 seconds. The CPU times of the GA should be added to the GABM times in reality since the GABM is firstly using the GA results.

The optimal solution found by GABM for the 12th scenario is presented in Figure 10. The used active bases and the routes of used four UAVs can be seen in the figure. The first UAV is taking off from Adana, monitoring the west side of the border, and turning back to Adana. The second UAV is also taking off from Adana, monitoring the remaining west side of the border, and landing to Diyarbakir. The third UAV is departing from Diyarbakır and landing at Batman. The last UAV is taking off and landing to Batman with covering the east side of the border. As seen all grid points are visited by one of the four UAVs.

Table 2. The tuning results.

\begin{tabular}{|c|c|c|c|c|c|c|c|c|}
\hline \multicolumn{5}{|c|}{ Parameters } & \multicolumn{4}{|c|}{ Fitness values for 30 runs } \\
\hline$\mu$ & $g_{\max }$ & $e$ & $P_{m}$ & $k$ & Min. & Mean & Max. & Std.dev. \\
\hline 80 & 125 & 0.1 & 0.1 & 3 & 8019991.1 & 8022027.8 & 8025389.9 & 1091.3 \\
\hline 80 & 125 & 0.1 & 0.1 & 5 & 8019097.6 & 8021529.4 & 8023435.9 & 896.5 \\
\hline 80 & 125 & 0.1 & 0.2 & 3 & 8019434.1 & 8021719.4 & 8023313.1 & 808.1 \\
\hline 80 & 125 & 0.1 & 0.2 & 5 & 8019113.8 & 8021858.7 & 8023700.7 & 1163.1 \\
\hline 80 & 125 & 0.2 & 0.1 & 3 & 8016928.8 & 8020533.4 & 8023854.4 & 1998.4 \\
\hline 80 & 125 & 0.2 & 0.1 & 5 & 8016608.8 & 8021417.1 & 8024069.0 & 1629.1 \\
\hline 80 & 125 & 0.2 & 0.2 & 3 & 8019478.7 & 8021155.0 & 8023131.7 & 718.9 \\
\hline 80 & 125 & 0.2 & 0.2 & 5 & 8016845.3 & 8021317.1 & 8025543.3 & 1024.2 \\
\hline 40 & 250 & 0.1 & 0.1 & 3 & 8020456.5 & 8022085.3 & 8024880.2 & 1000.4 \\
\hline 40 & 250 & 0.1 & 0.1 & 5 & 8019328.7 & 8021403.9 & 8023808.3 & 899.1 \\
\hline 40 & 250 & 0.1 & 0.2 & 3 & 8019150.8 & 8023526.2 & 8027532.6 & 2387.7 \\
\hline 40 & 250 & 0.1 & 0.2 & 5 & 8019166.4 & 8022191.1 & 8024364.9 & 1320.9 \\
\hline 40 & 250 & 0.2 & 0.1 & 3 & 8019137.3 & 8021383.1 & 8023118.5 & 758.2 \\
\hline 40 & 250 & 0.2 & 0.1 & 5 & 8018223.7 & 8021876.6 & 8025219.9 & 1169.1 \\
\hline 40 & 250 & 0.2 & 0.2 & 3 & 8017936.9 & 8021321.2 & 8024272.5 & 1584.4 \\
\hline 40 & 250 & 0.2 & 0.2 & 5 & 8017811.6 & 8021217.6 & 8023878.5 & 1442.1 \\
\hline 20 & 500 & 0.1 & 0.1 & 3 & 8016797.7 & 8023057.7 & 8026972.6 & 2276.1 \\
\hline 20 & 500 & 0.1 & 0.1 & 5 & 8016518.3* & 8022263.2 & 8025954.5 & 1872.1 \\
\hline 20 & 500 & 0.1 & 0.2 & 3 & 8017019.3 & 8023629.8 & 8027532.6 & 3046.1 \\
\hline 20 & 500 & 0.1 & 0.2 & 5 & 8017472.8 & 8023218.3 & 8026627.4 & 2299.4 \\
\hline 20 & 500 & 0.2 & 0.1 & 3 & 8019458.8 & 8023270.7 & 8027532.6 & 2575.1 \\
\hline 20 & 500 & 0.2 & 0.1 & 5 & 8017343.7 & 8021898.6 & 8024866.8 & 2096.1 \\
\hline 20 & 500 & 0.2 & 0.2 & 3 & 8017324.2 & 8021759.5 & 8025381.9 & 2080.7 \\
\hline 20 & 500 & 0.2 & 0.2 & 5 & 8017885.9 & 8021795.8 & 8026330.2 & 1916.3 \\
\hline
\end{tabular}

* In the best solution according to the fitness value calculation 2 UAVs are flying $825.9 \mathrm{~km}$. 
Table 3. The results.

\begin{tabular}{|c|c|c|c|c|c|c|c|c|c|c|}
\hline \multirow[b]{3}{*}{$\begin{array}{c}\text { Sce. } \\
\#\end{array}$} & \multicolumn{6}{|c|}{ GA } & \multirow{2}{*}{\multicolumn{2}{|c|}{ GABM }} & \multirow{2}{*}{\multicolumn{2}{|c|}{$\begin{array}{c}\text { Improvement } \\
(\%)\end{array}$}} \\
\hline & \multicolumn{2}{|c|}{ Best } & \multicolumn{2}{|c|}{ Mean } & \multicolumn{2}{|c|}{ Worst } & & & & \\
\hline & $\begin{array}{c}\text { \# of } \\
\mathrm{UAV}(\mathrm{s})\end{array}$ & $\begin{array}{c}\text { Total } \\
\text { flight dist. } \\
(\mathrm{km} .)\end{array}$ & $\begin{array}{c}\text { \# of } \\
\text { UAV(s) }\end{array}$ & $\begin{array}{c}\text { Total } \\
\text { flight } \\
\text { dist. } \\
(\mathrm{km} .)\end{array}$ & $\begin{array}{c}\text { \# of } \\
\mathrm{UAV}(\mathrm{s})\end{array}$ & $\begin{array}{c}\text { Total } \\
\text { flight } \\
\text { dist. } \\
(\mathrm{km} .) \\
\end{array}$ & $\begin{array}{c}\text { \# of } \\
\text { UAV(s) }\end{array}$ & $\begin{array}{c}\text { Flight } \\
\text { dist. } \\
\text { (km.) }\end{array}$ & $\begin{array}{c}\text { \# of } \\
\text { UAV(s) }\end{array}$ & $\begin{array}{c}\text { Total } \\
\text { flight } \\
\text { dist. } \\
(\mathrm{km} .) \\
\end{array}$ \\
\hline 1 & 1 & 1504.9 & 1 & 1504.9 & 1 & 1504.9 & 1 & 1504.9 & - & - \\
\hline 2 & 1 & 1419.3 & 1 & 1419.3 & 1 & 1419.3 & 1 & 1419.3 & - & - \\
\hline 3 & 1 & 1415.7 & 1 & 1415.7 & 1 & 1415.7 & 1 & 1415.7 & - & - \\
\hline 4 & 1 & 1554.4 & 1 & 1554.4 & 1 & 1554.4 & 1 & 1554.4 & - & - \\
\hline 5 & 2 & 3618.8 & 2 & 3618.8 & 2 & 3618.8 & 2 & 1718.4 & - & 52.51 \\
\hline 6 & 1 & 1419.3 & 1 & 1419.3 & 1 & 1419.3 & 1 & 1419.3 & - & - \\
\hline 7 & 1 & 1415.7 & 1 & 1415.7 & 1 & 1415.7 & 1 & 1415.7 & - & - \\
\hline 8 & 8 & 13474.8 & 8 & 13474.8 & 8 & 13474.8 & 2 & 1887.5 & 400 & 85.99 \\
\hline 9 & $2 *$ & $1710.3^{*}$ & 2 & 1919.4 & 2 & 1986.6 & $2 * *$ & $1204.5^{* *}$ & - & 29.57 \\
\hline 10 & $3 * * *$ & $2126.6 * * *$ & 3 & 2184.6 & 3 & 2234.4 & $2 * * *$ & $1298.7 * * *$ & 33 & 38.93 \\
\hline 11 & $4 * * *$ & $2406.8 * * *$ & 4 & 2567.1 & 4 & 2718.8 & $3 * * *$ & $1444.1 * * *$ & 25 & 39.99 \\
\hline 12 & $5 * * *$ & $2840.2 * * *$ & 5 & 2900.1 & 5 & 2955.5 & $4 * * *$ & $1793.9 * * *$ & 20 & 36.83 \\
\hline
\end{tabular}

Table 4. The details about the GABM results and the scenarios.

\begin{tabular}{|c|c|c|c|c|c|c|c|}
\hline \multirow[b]{2}{*}{$\begin{array}{l}\text { Sce. } \\
\#\end{array}$} & \multirow[b]{2}{*}{$\begin{array}{c}\# \text { of } \\
\text { variables }\end{array}$} & \multirow[b]{2}{*}{$\begin{array}{c}\text { \# of } \\
\text { constraints }\end{array}$} & \multirow[b]{2}{*}{$\begin{array}{l}\text { Flight range } \\
(\mathrm{km} .)\end{array}$} & \multicolumn{4}{|c|}{ GABM } \\
\hline & & & & $\begin{array}{c}\text { \# of } \\
\mathrm{UAV}(\mathrm{s})\end{array}$ & $\begin{array}{l}\text { Singular } \\
\text { flight dist. } \\
\quad(\mathrm{km} .)\end{array}$ & $\begin{array}{c}\text { Singular } \\
\text { remaining } \\
\text { flight range } \\
(\mathrm{km} .)\end{array}$ & $\begin{array}{l}\text { Singular } \\
\text { flight } \\
\text { route }\end{array}$ \\
\hline 1 & 23562 & 23411 & 3000 & 1 & 1504.9 & 1495.1 & $1-\ldots-152$ \\
\hline 2 & 23562 & 23411 & 3000 & 1 & 1419.3 & 1580.7 & $1-\ldots-152$ \\
\hline 3 & 23562 & 23411 & 3000 & 1 & 1415.7 & 1584.3 & $1-\ldots-152$ \\
\hline 4 & 23562 & 23411 & 3000 & 1 & 1554.4 & 1445.6 & $1-\ldots-152$ \\
\hline 5 & 46971 & 23566 & 1500 & 2 & $\begin{array}{c}390.9 \\
1327.5\end{array}$ & $\begin{array}{c}1109.1 \\
172.4\end{array}$ & $\begin{array}{c}33-34-\ldots-152 \\
32-31-\ldots-1\end{array}$ \\
\hline 6 & 23562 & 23411 & 1500 & 1 & 1419.3 & 1580.7 & $1-\ldots-152$ \\
\hline 7 & 23562 & 23411 & 1500 & 1 & 1415.7 & 1584.3 & $1-\ldots-152$ \\
\hline 8 & 46971 & 23566 & 1500 & 2 & $\begin{array}{c}1490.7 \\
396.8\end{array}$ & $\begin{array}{c}9.3 \\
1103.2\end{array}$ & $\begin{array}{c}144-143-\ldots-1 \\
145-146-\ldots-152\end{array}$ \\
\hline 9 & 48825 & 23566 & 1000 & 2 & $\begin{array}{l}820.8 \\
383.7\end{array}$ & $\begin{array}{l}179.2 \\
616.3\end{array}$ & $\begin{array}{c}121-120-\ldots-1 \\
122-123-\ldots-152\end{array}$ \\
\hline 10 & 48825 & 23566 & 750 & 2 & $\begin{array}{l}747.4 \\
551.3\end{array}$ & $\begin{array}{c}2.6 \\
198.7\end{array}$ & $\begin{array}{c}1-\ldots-96-97 \\
152-\ldots-99-98\end{array}$ \\
\hline 11 & 73161 & 23721 & 600 & 3 & $\begin{array}{l}599.5 \\
441.6 \\
403.0\end{array}$ & $\begin{array}{c}0.5 \\
158.4 \\
197.0\end{array}$ & $\begin{array}{c}112-111-\ldots-36-35 \\
152-\ldots-114-113 \\
34-33-\ldots-1\end{array}$ \\
\hline 12 & 97497 & 23876 & 500 & 4 & $\begin{array}{l}499.2 \\
497.2 \\
403.0 \\
394.5 \\
\end{array}$ & $\begin{array}{c}0.8 \\
2.8 \\
97.0 \\
105.5 \\
\end{array}$ & $\begin{array}{c}120-121-\ldots-152 \\
35-36-\ldots-74-75 \\
76-77-\ldots-118-119 \\
34-33-\ldots-1 \\
\end{array}$ \\
\hline
\end{tabular}

\section{Conclusion}

In this study, the UAVRP is adapted for border security missions. A new mathematical model is developed inspired by literature. The model is combined with a problem-specific GA to solve the UAVRP. The designed GABM is trying to solve the problem by initializing GA 30 times in the beginning. Then the model is using the " $m$ " value of the best GA result as a constant. If the model solves the problem with the determined " $m$ " value, then the algorithm decreases the " $m=m-1$ " and rerun the model. If the model cannot find a solution with the determined " $m$ " value, then GABM presents the previous solution as optimal. As far as known, GA and GABM algorithms are used for the first time in the literature in a UAVRP defined for border monitoring missions. 
Table 5. The CPU times.

\begin{tabular}{ccccc}
\hline & \multicolumn{3}{c}{ GA (s.) } & GABM \\
\cline { 2 - 4 } Sce.\# & Best & Mean & Worst & $($ s.) \\
\hline 1 & 79.39 & 91.39 & 111.86 & 3.23 \\
2 & 74.65 & 88.17 & 98.47 & 3.78 \\
3 & 71.89 & 82.94 & 97.49 & 3.11 \\
4 & 74.90 & 82.04 & 92.51 & 2.92 \\
5 & 82.61 & 91.57 & 100.99 & 4.44 \\
6 & 80.84 & 91.51 & 105.95 & 3.78 \\
7 & 81.61 & 95.75 & 111.58 & 3.11 \\
8 & 81.76 & 88.97 & 96.19 & 3.16 \\
9 & 89.55 & 100.71 & 116.73 & 5.04 \\
10 & 92.64 & 101.32 & 114.92 & 5.65 \\
11 & 98.87 & 106.29 & 122.17 & 24.60 \\
12 & 91.81 & 104.87 & 121.09 & 46.39 \\
\hline
\end{tabular}

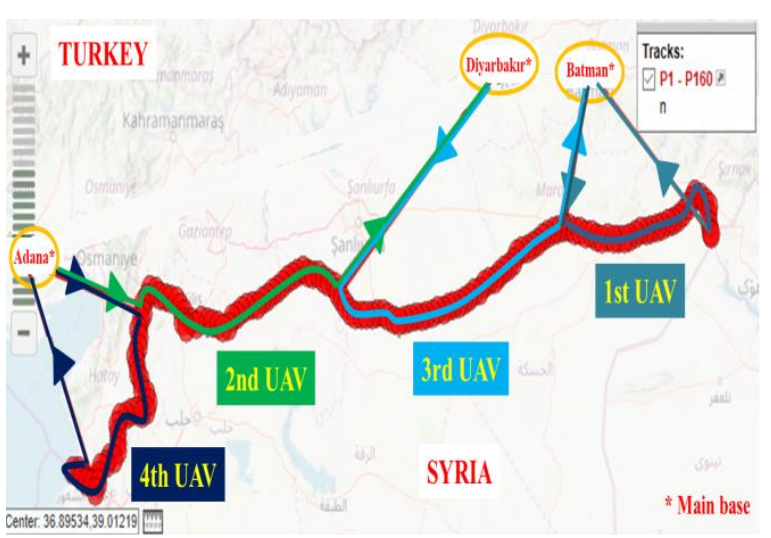

Figure 10. The optimal route for scenario \#12 with 4 UAVs

The borderline between Turkey and Syria is selected for the case study. Bayraktar UAV is chosen considering the usage of it in real life. 12 realistic scenarios are generated covering four airbases and 152 grid points on the borderline. While considering scenarios, the usage of active bases and the number of daily patrols done by UAVs are changed. The scenarios are solved with GA and GABM. In half of the scenarios, GABM improved the GA results and decreased the used number of UAVs and the total travel distances. Especially for more complex scenarios, GABM developed the results much effectively in reasonable CPU times.

For future research, more realistic 3-D scenarios can be tried. Simulation models can be integrated with proposed hybrid algorithms to simulate the intruder detections in the border with a more dynamic perspective.

\section{References}

[1] Kaza, S., Wang, Y., \& Chen, H. (2007). Enhancing border security: Mutual information analysis to identify suspect vehicles, Decision Support Systems, $43,199-210$.

[2] Sun, Z., Wang, P., Vuran, M.C., Al-Rodhaan, M. A., Al-Dhelaan, A.M., \& Akyildiz, I.F. (2011). BorderSense: Border patrol through advanced wireless sensor networks, Ad Hoc Networks, 9, 468-
477.

[3] Owen, A., Duckworth, G., \& Worsley, J. (2012). OptaSense: Fibre optic distributed acoustic sensing for border monitoring, in Proc. of the 2012 European Intelligence and Security Informatics Conference, 22-24 Aug., Odense, Denmark [Online]. Available: IEEE Xplore, http://www.ieee.org. [Accessed: 16 September 2020].

[4] Hare, J., Gupta, S., \& Wilson, J. (2015). Decentralized smart sensor scheduling for multiple target tracking for border surveillance, in Proc. of the 2015 IEEE Int. Conf. on Robotics and Automation, ICRA 2015, 26-30 May, Seattle, Washington, [Online]. Available: IEEE Xplore, http://www.ieee.org. [Accessed: 16 September 2020].

[5] Karabulut, E., Aras, N., \& Altınel, İ.K. (2017). Optimal sensor deployment to increase the security of the maximal breach path in border surveillance, European Journal of Operational Research, 259, 19-36.

[6] Alkhathami, M., Alazzawi, L., \& Elkateeb, A. (2017). Large scale border security systems modeling and simulation with OPNET, in Proc. of the 2017 IEEE 7th Annual Computing and Communication Workshop and Conference, CCWC 2017, 09-11 Jan., Las Vegas, USA.

[7] Arjun, D., Indukala, P.K., \& Unnikrishna Menon, K.A. (2017). Border surveillance and intruder detection using wireless sensor networks: A brief survey, in Proc. of the 2017 Int. Conf. on Communication and Signal Processing, ICCSP 2017, 06-08 April, Chennai, India.

[8] Lessin, A.M., Lunday, B.J., \& Hill, R.R. (2018). A bilevel exposure-oriented sensor location problem for border security, Computers and Operations Research, 98, 56-68.

[9] Matveev, A.S., Teimoori, H., \& Savkin, A.V. (2011). A method for guidance and control of an autonomous vehicle in problems of border patrolling and obstacle avoidance, Automatica, 47, 515-524.

[10] Tanas, M., Holubowicz, W., Adamczyk, A., \& Taberski, G. (2011). The TALOS Project. EU wide robotic border guard system, in Proc. of the 2011 16th Int. Conf. on Methods \& Models in Automation \& Robotics, 22-25 Aug., Miedzyzdroje, Poland.

[11] Tanas, M., Taberski, G., Hołubowicz, W., Samp, K., Sprońska, A., Główka, J., \& Maciaś, M. (2012). The TALOS project - autonomous robotic patrol vehicles, in Proc. of the 2012 European Intelligence and Security Informatics Conference, 22-24 Aug., Odense, Denmark.

[12] Girard, A.R., Howell, A.S., \& Hedrick, J.K. (2004). Border patrol and surveillance missions using multiple unmanned air vehicles, in Proc. of the 43rd IEEE Conference on Decision and Control, 2004, 14-17 Dec., Atlantis, Bahamas. 
[13] Blazakis, J. (2006). Border security and unmanned aerial vehicles, Connections, 5(2), 154-159.

[14] Matveev, A.S. Teimoori, H., \& Savkin, A.V. (2010). A method for navigation of an autonomous vehicle for border patrol, in Proc. of the 2010 American Control Conference, 30 June-02 July, Marriott Waterfront, Baltimore, USA.

[15] Haddal, C.C., \& Gertler, J. (2010). Homeland security: Unmanned aerial vehicles and border surveillance, Congressional Research Service Report for Congress, RS21698, USA, [Online]. Available:

https://nsarchive2.gwu.edu/NSAEBB/NSAEBB5 27-Using-overhead-imagery-to-track-domesticUS-targets/documents/EBB-Doc24.pdf, [Accessed: 16 September 2020].

[16] Ortiz-Rivera, E.I., Estela, A., Romero, C., \& Valentin, J.A. (2012). The use of UAVS in USA's security by an engineering education approach, in Proc. of the 2012 IEEE Conference on Technologies for Homeland Security (HST), 13-15 Nov., Waltham, USA.

[17] Moss, V., Jones, D., \& Nwaneri, S. (2012). Analysis of homeland security and economic survey using special missions unmanned aerial vehicle utilities, in Proc. of the 2012 IEEE International Geoscience and Remote Sensing Symposium, 22-27 July, Munich, Germany.

[18] Office of Inspector General (2014). U.S. customs and border protection's unmanned aircraft system program does not achieve intended results or recognize all costs of operations", Department of Homeland Security Report, OIG-15-17, USA, [Online].

Available: https://www.oig.dhs.gov/assets/Mgmt/2015/OIG _15-17_Dec14.pdf, [Accessed: 16 September 2020].

[19] Bein, D., Bein, W., Karki, A., \& Madan, B.B. (2015). Optimizing border patrol operations using unmanned aerial vehicles, in Proc. of the 2015 12th International Conference on Information Technology - New Generations, 13-15 April, Las Vegas, USA.

[20] Półka, M., Ptak, S., \& Kuziora, L. (2017). The use of UAV's for search and rescue operations, Procedia Engineering, 192, 748-752.

[21] Cică, C., \& Filipoaia, L. (2016). Border surveillance optimization using a multi-objective mathematical model, in Proc. of the 2016 IEEE Int. Conf. on Electronics, Computers and Artificial Intelligence, ECAI 2016, 30 June-02 July, Ploiesti, Romania.

[22] Çelik, G., \& Sabuncuoğlu, İ. (2007). Simulation modelling and analysis of a border security system, European Journal of Operational Research, 180, 1394-1410.

[23] Jenkins, J.L., Marquardson, J., Proudfoot, J.G., Valacich, J.S., Golob, E., \& Nunamaker, Jr., J.F. (2013). The Checkpoint Simulation: A tool for informing border patrol checkpoint design and resource allocation, in Proc. of the 2013 European Intelligence and Security Informatics Conference, 12-14 Aug., Uppsala, Sweden.

[24] Muaafa, M., \& Ramirez-Marquez, J.E. (2017). Biobjective evolutionary approach to the design of patrolling schemes for improved border security", Computers \& Industrial Engineering, 107, 74-84.

[25] Ackleson, J. (2003). Directions in border security research, The Social Science Journal, 40, 573-581.

[26] Gravelle, T.B. (2018). Politics, time, space, and attitudes toward US-Mexico border security, Political Geography, 65, 107-116.

[27] Fisher, D.X.O. (2018). Situating border control: Unpacking Spain's SIVE border surveillance assemblage, Political Geography, 65, 67-76.

[28] Dalamagkidis, K. Valavanis, K.P., \& Piegl, L.A. (2008). On unmanned aircraft systems issues, challenges and operational restrictions preventing integration into the National Airspace System, Progress in Aerospace Sciences, 44, 503-519.

[29] Gupte, S., Mohandas, P.I.T., \& Conrad, J.M. (2012). A survey of quadrotor unmanned aerial vehicles, in Proc. of the 2012 IEEE Southeastcon, 15-18 March, Orlando, USA.

[30] Yu, X., \& Zhang, Y. (2015). Sense and avoid technologies with applications to unmanned aircraft systems: Review and prospects, Progress in Aerospace Sciences, 74, 152-166.

[31] Mcfadyen, A., \& Mejias, L. (2016). A survey of autonomous vision-based see and avoid for unmanned aircraft systems, Progress in Aerospace Sciences, 80, 01-17.

[32] Eksioglu, B., Vural, A.V., \& Reisman, A. (2009). The vehicle routing problem: A taxonomic review, Computers \& Industrial Engineering, 57, 14721483.

[33] Braekers, K., Ramaekers, K., \& Nieuwenhuyse, I.V. (2016). The vehicle routing problem: State of the art classification and review, Computers \& Industrial Engineering, 99, 300-313.

[34] Gansterer, M., \& Hartl, R.F. (2018). Collaborative vehicle routing: A survey, European Journal of Operational Research, 268, 1-12.

[35] Tlili, T., Faiz, S., \& Krichen, S. (2014). A hybrid metaheuristic for the distance-constrained capacitated vehicle routing problem, Procedia Social and Behavioral Sciences, 109, 779-783.

[36] Letchford, A.N., \& Salazar-González, J.-J. (2019). The capacitated vehicle routing problem: Stronger bounds in pseudo-polynomial time, European Journal of Operational Research, 272, 24-31.

[37] Montoya-Torres, J.R., Franco, J.L., Isaza, S.N., Jiménez, H.F., \& Herazo-Padilla, N. (2015). A literature review on the vehicle routing problem with multiple depots, Computers \& Industrial 
Engineering, 79, 115-129.

[38] Bektas, T. (2006). The multiple traveling salesman problem: an overview of formulations and solution procedures", Omega, 34, 209-219.

[39] Kaempfer, Y., \& Wolf, L. (2018). Learning the multiple traveling salesmen problem with permutation invariant pooling networks, CORR, abs/1803.09621, 1-17.

[40] Coutinho, W.P., Battarra, M., \& Fliege, J. (2018). The unmanned aerial vehicle routing and trajectory optimisation problem, a taxonomic review, Computers \& Industrial Engineering, 120, 116-128.

[41] Pandey, P., Shukla, A., \& Tiwari, R. (2017). Aerial path planning using meta-heuristics: A survey, in Proc. of the 2017 Second International Conference on Electrical, Computer and Communication Technologies (ICECCT), 22-24 Feb., Coimbatore, India.

[42] Zhao, Y., Zheng, Z., \& Liu, Y. (2018). Survey on computational-intelligence-based UAV path planning, Knowledge-Based Systems, 158, 54-64.

[43] Seyis, A., Karacin, Y., \& Ozkan, O. (2016). Optimal path planning with minimum number of UAVs by using genetic algorithm", in Proc. of the 28th European Conference on Operational Research (EURO 2016), 03-06 July, Poznan, Poland.

[44] Kaya, M., \& Ozkan, O. (2018). Sinır koruma görevi için insansız hava araçlarının rotalanması probleminin genetik algoritma ile eniyilenmesi, in Proc. of the 38. Ulusal Yöneylem Araştırmast ve Endüstri Mühendisliği Kongresi (YAEM 2018), 26 29 June, Eskişehir, Turkey.

[45] Ozkan, O. (2018). İnsansız hava araçları ile Türkiye'deki orman yangınlarının tespiti probleminin tavlama benzetimi ile eniyilenmesi, in Proc. of the 38. Ulusal Yöneylem Araştırmast ve Endüstri Mühendisliği Kongresi (YAEM 2018), 26 29 June, Eskişehir, Turkey.
[46] Yang, L., Qi, J., Xiao, J., \& Yong, X. (2014). A literature review of UAV 3D path planning, in Proc. of the 2014 11th World Congress on Intelligent Control and Automation, 29 June-04 July, Shenyang, China.

[47] Khan, M.A., Safi, A., Qureshi, I.M., \& Khan, I.U. (2017). Flying Ad-Hoc Networks (FANETs): A review of communication architectures, and routing protocols, in Proc. of the 2017 First International Conference on Latest trends in Electrical Engineering and Computing Technologies (INTELLECT), 15-16 Nov., Karachi, Pakistan.

[48] T.C. Cumhurbaşkanlığı, Türk Savunma Sanayii Başkanlığı (2021). SSB - Türk Savunma Sanayii Ürün Kataloğu [online]. Available from: SSB TÜRK SAVUNMA SANAYIII ÜRÜN KATALOĞU, [Accessed: 16 September 2020].

[49] Baykar Savunma (2021). Bayraktar TB-2 [online]. Available from: BAYKAR İnsansız Hava Aracı Sistemleri (baykarsavunma.com), [Accessed: 16 September 2020].

Muhammed Kaya received his B.Sc. degree in Industrial Engineering from Turkish Air Force Academy, National Defence University, Istanbul, in 2018. He is a First Lieutenant in Turkish Air Force.

(iD) https://orcid.org/0000-0001-9410-7367

Omer Ozkan received his B.Sc. degree in Industrial Engineering from Turkish Air Force Academy, Istanbul, in 2002. He received his M.Sc. degree in Industrial Engineering from Dokuz Eylul University, Izmir, in 2010 and the Ph.D. degree in Industrial Engineering from National Defence University, Istanbul, in 2016. He is currently an Assistant Professor of Operations Research in Industrial Engineering Department, Turkish Air Force Academy, National Defence University. His research interests include metaheuristics, optimization, and network analysis.

(iD) https://orcid.org/0000-0002-3839-2754

An International Journal of Optimization and Control: Theories \& Applications (http://ijocta.balikesir.edu.tr)

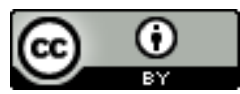

This work is licensed under a Creative Commons Attribution 4.0 International License. The authors retain ownership of the copyright for their article, but they allow anyone to download, reuse, reprint, modify, distribute, and/or copy articles in IJOCTA, so long as the original authors and source are credited. To see the complete license contents, please visit http://creativecommons.org/licenses/by/4.0/. 